\title{
Game based learning of lean manufacturing: decreasing personnel resistance
}

\author{
Elena Ganebnykh ${ }^{1 *}$, Irina Altsybeeva ${ }^{1}$, Ekaterina Gurova ${ }^{1}$ \\ ${ }^{1}$ Vyatka State University, 610000 Kirov, Russia
}

\begin{abstract}
Developing production systems based on the principles of lean manufacturing is getting more and more popular nowadays. At the initial stage one of the main issues is high personnel resistance. Training helps to overcome the staff resistance. The research aims at proving a hypothesis of the positive effect of game based learning methods with imitating the production process on lessening the personnel resistance at the stage of implementing lean manufacturing in the company. The paper describes the game model worked out by the authors. This model imitates the production process consisting of successive operations. In the model two main factors influencing the productivity are taken into account: defective goods and stand by time. The model was tested at an enterprise producing children toys made of rubber and plastic. As a result, the participants have learnt some basic principles of lean manufacturing, as well as a principle of forming the key index of Overall Equipment Effectiveness (OEE). The task of lessening the personnel resistance was solved, the participants got to understand the necessity of improving the production process. The model is universal and is easily applicable to any productions and non-production processes. The authors believe the research has a broad sphere of applicability.
\end{abstract}

\section{Introduction}

A shift to market economy made many Russian enterprises focus their attention on the users meeting any of their requirements, as well as on sales-markets forecasting their depth and dynamics and stimulating the demand. As a result, while in the advanced economies they have been studying and implementing the Japanese philosophy of sustainable development of production processes that was shown in 1986 by the Japanese economist Masaaki Imai in his book «Kaizen: The Key to Japan's Competitive Success» [7], in Russia production aspects actually have not been improved, they are staying on the level of the 90-s of the 20th century. They started to implement the system of lean manufacturing only from 2004, mostly at big, not to say "gigantic" enterprises.

The basic principles, trends, ways and methods of implementing the lean manufacturing system have been widely researched by foreign and Russian scientists and described in scientific and publicistic works $[5,7,8,13,14,11]$. The value of the system of lean manufacturing is difficult to overestimate, it is the most likely that this philosophy has contributed to the fact that the Japanese economy not just quickly recovered after the WWII, but also has become one of leaders of the world business.

The advantage of developing production systems on the principles of lean manufacturing on a long-term horizon could be demonstrated by the results of the world-famous producers: Toyota, Honda, Nissan, Canon, SIBUR, RUSAL, KAMAZ, TATNEFT and many others which have pushed on to the next level due to the system of lean manufacturing $[1,3,15,16,17]$. Still a 10-20-years gap in developing and mastering the methods of lean manufacturing between Russia and Japan, the USA, Germany, as well as other mature economies is striking indeed.

Having begun implementing kaizen-principles, entrepreneurs in Russia admit that the process is mainly interfered with by resistance of the employees at their working places [2]. It could be explained from the scientific viewpoint: implementing a new system causes organizational changes connected with re-organizing the organization itself, which is a fundamental change, urged by the necessity of forming a new organizational philosophy of production. Any organizational changes, especially the basic ones, lead to the employees' resistance which is caused by the fear of uncertainty, loss of safety, loss of power, lack of any reliable information, conservatism (habit). Having overcome this resistance at an industrial enterprise, at assembly line production, each employee comes to understand that the result is dependable on the work of each participant and that at considering and implementing the kaizen system in a daily production process (operation) which seems improved one can find some elements which require optimization. On the basis of eliminating the shortcomings the time necessary for an operation shortens, the amount of defective goods decreases, the

\footnotetext{
Corresponding author: ganebnykh@mail.ru
} 
quality improves, the stand-by time also shortens, etc. As a result at each working place labour effort is eased, and the wages grow. The personnel who have experienced this effect as a result of implementing the system are shocked, and at the same time they feel grateful [10]. The workers get surer and feel a considerable importance of their part in the whole production process, and, most of all, they understand their responsibility for the work done.

Thus the main issue of implementing the system of lean manufacturing is resistance of the employees of the enterprise. How can this issue be solved? How can one explain to the personnel effectively that the main principles of lean production (little setup time, error protection, preventing defective goods, shortening of stand by time) do good not just to the enterprise but as well to them personally?

In this case one can rely on the instruction of implementing management principles of Toyota: it is necessary to teach the employees to contemplate on what they have learnt, to use their knowledge, and to think of the process and improve it so that it would lead to growth and flourishing of the enterprise at a long-term horizon [12].

So, the main method of overcoming the personnel resistance is training and there are many methods of doing it. A huge amount of modelings and games develops dynamically [18]. We think that the most telling and close to reality way is the method of game based imitating modeling:

- «Imitative modeling» means that such models of production process occur within which one cannot calculate and foresee the result beforehand [4];

- Imitating a production process (cycle), taking into account the impact of negative factors, can in a game form demonstrate efficiency/inefficiency of the production actions.

Thus, the key hypothesis of the research consists in stating a positive role of games based learning which is connected with imitating the production process for the sake of lessening the personnel resistance at the stage of implementing lean manufacturing system at an enterprise.

We think that games based learning not just clearly shows the results of the personnel actions during the production cycle, but also demonstrates the level of the factors' influence on the productivity, thus enhancing the responsibility of each one participating in the production cycle.

\section{Methods}

The main part of the research was devoted to creating a game model imitating the production process. The model takes into account two factors which influence efficiency ("wastes" in terms of lean manufacturing): defective goods and stand-by time. As a result, the gamers learn how to calculate the key index, i.e. Overall Equipment Effectiveness (OEE) which is a recognized world standard if calculating efficiency [9]. This index is used as an indicator of efficiency increase.
At the stage of first introducing lean manufacturing principles in the work of the company personnel resistance is unavoidable. One of the ways of decreasing this resistance is personnel training. Games based learning in training the personnel helps to introduce lean manufacturing tools to them and to clearly demonstrate the principles and approaches of this system.

In order to make the game as close to real life as possible during production it is necessary to collect the following data on a modelled assembly line: cycle time (TC), average rate of defective goods for a certain line (D), and average standby time due to machinery break down (WB).

The game consists in imitating an assembly line with five stations responsible for successive operations. Each station is represented by one gamer (operator). Each operator, beginning with the first one simulated certain actions with a component (a gambling chip): doing well, producing defective goods, or standing-by. The first operator can stand by only because of machinery breakdown, the next operators can also stand by due to lack of a certain component (for example, in case the previous operator has made a defective component).

A 6-sided die can be used as a random number generator. Thus, there is a range of possible variants from 1 to 6 . Knowing the average rate of defective goods on the line it is possible to determine a number of conditioned variants at a die roll meaning "defective goods". Should one die be used the minimum possible variant meaning "defective goods" is one of its planes. The probability of that plane is $1 / 6$ of all the throws, and each gamer is supposed to throw the die. It means that the average percentage of defective goods is to be $15 \%$ at each level. This figure does not coincide with the real state of affairs, it is overrated. But exaggeration of defective goods index can demonstrate the effect of lessening the wastes caused by this reason.

A number of stand-byes due to machinery breakdown is calculated in the same way. Thus, we get at minimum that: one of the planes denotes "defective goods", one machinery break and a stand-by, and four other planes stand for a useful action.

In the beginning, before playing the game, it is necessary either to determine the amount of the product to produce, or restrict the number of gambling chips. In the first case, it is possible to show how much time is spent on producing a certain amount of the product, in the second case it is possible to show the yield at a restricted period of time (a number of moves).

After the run of the first iteration the players get to know about low efficiency of the operating system. The described variant with one 6-sided die and 18 gambling chips the output is usually 1-2 details (gambling chips). The remaining chips belong to in-process inventory. During the imitation, each operator is offered to fill in the table reflecting their losses at each move (Table 1). Taking into account the results shown in Table 1 each participant counts their own indexes $(1,2,3)$ :

$$
\begin{gathered}
K_{\text {availability }}=1-\sum_{\text {availability loss }} / n \\
K_{\text {performance }}=1-\sum_{\text {performance loss }} / n
\end{gathered}
$$




$$
K_{\text {quality }}=1-\Sigma_{\text {quality loss }} / n
$$

Table 1. Wastes during the game.

\begin{tabular}{|l|l|l|l|l|l|l|l|}
\hline \multirow{2}{*}{\multicolumn{1}{c|}{ Waste }} & \multicolumn{5}{c|}{ I iteration } & \multirow{2}{*}{ Sum } \\
\cline { 2 - 7 } & 1 & 2 & 3 & 4 & $\ldots$ & $\mathrm{n}$ & \\
\hline Lacking detail & & & & & & & \\
\hline Machinery breakdown & & & & & & & \\
\hline Defective goods & & & & & & & \\
\hline
\end{tabular}

On the basis of the calculations the participants themselves estimate their overall equipment efficiency (4):

$$
\text { OEE }=K_{\text {availability }} * K_{\text {performance }} * K_{\text {quality }} * 100 \%
$$

After finishing the first iteration and drawing the conclusion the trainer offers to make one improvement. This improvement consists in eliminating one of losses. Then the second iteration takes place, it brings more success. It is necessary to calculate the coefficients of availability, performance, and quality, as well as to estimate the OEE. Comparing the OEE of the first and the second iterations shows improvement as performance coefficient grows due to eliminating one of loss kinds.

During the third rub the loss left is eliminated. It is evident that at eliminating the second loss the output is $100 \%$. Like before, the conclusion is drawn and the coefficients and the OEE are calculated. As there are no losses, the OEE is $100 \%$.

To transfer the skills acquired at the imitation game to production process all the gamers should calculate the real OEE for their production lines and suggest some improvement of the processes ("kaizen").

The game can be improved, made more complex introducing some economical grounding into it. It is possible to set a price of every chip (die), of the ready goods, as well as to set constant expenses (wages imitation, electricity costs, costs, space rental, etc.), as well as variable costs (machinery maintenance for eliminating machinery breakdowns). Calculating economical effect at each iteration shows the results of the production line operating.

The game can be varied, for example, the production input can be done in lots of several chips, or two or more 6-sided dies can be used for a more true-to-life imitation of a definite production.

It is evident that the exact calculation of production indexes allows to imitate production process really trueto-life. Still we think that the simplest variant with one 6-sided die demonstrates the influence of losses on the performance to the gamers and reduces their resistance at the initial stage of implementing lean manufacturing conception at an enterprise

\section{Results}

The worked-out model was tested at an enterprise producing children toys from rubber and plastic. The rotary line of producing plastisol intermediates (heads) for dolls was chosen as the experimental area. Plastisol is the input, a formed intermediate for assembling the finished goods is the output. The line consists of 12 successive operations:

1. Placing the initial shapes on the electroformed moulds;

2. Filling the first halves of the shapes with plastisol;

3. Closing the first halves of the shapes hermetically;

4. Turning over the electroformed moulds;

5. Filling the second halves of the shapes with plastisol;

6. Closing the second halves of the shapes hermetically;

7. Turning over the electroformed moulds for equidistribution of plastisol in the shape;

8. Putting the disks with electroformed moulds into the rotary oven where plastisol gelatinates. The process is automatized, at the end the shapes go out for making a hollow;

9. Taking out the shapes from the first half of the form;

10. Turning over the electroformed moulds;

11. Taking out the shapes from the second half of the form;

12. Cutting off the edges of plastisol of the shapes.

They produce 10 intermediates during a cycle. The time of a cycle is 425 seconds + baking time (480-960 seconds depending on the model).

Possibility of making defective goods was of interest. It was observed that actually at all the stages when hand work of an operator is used some defective goods are made. About 2.5\% defective goods are produced at the seventh stage at turning over the electroformed moulds: insufficient or uneven turning over leads to defective distribution of the material in the form, as a result the shape gets a non-commodity look. About 3\% defective goods are formed at the last stage at cutting off the edges of plastisol of the shapes: hand cutting off is vulnerable to human error.

At producing 208-320 items (depending on the model) during an 8-hour shift 11-17 items of goods are with defects. Each month this loss accounts for 242-374 items of goods which is about the amount of the output during one shift. So, in fact one day monthly the enterprise produces just defective goods. And the costs, both constant and variable remain the same.

An important feature of the line is the fact that defective goods are produced even before putting the shapes into the oven. Which means that all the work done with a faulty, defective shape, up to its taking out, cause direct losses to the enterprise.

There are two analogous lines at the enterprise. One of them was made in Italy, it was bought in 2009 , it is in a good technical form and is maintained regularly according to the producer's instructions. The second line is much older and is maintained only at current planned repairs. As we did not have an opportunity to see any machinery breakdowns or repairs, the statistical data were asked for which showed that during the last 3 
months the line was standing for 8 working days because the oven was repaired ( $12 \%$ working time).

To demonstrate it more clearly, game modelling included two kinds of losses: defective goods $(5,5 \%)$ and stand-by (12\%). Two 6-sided dies were used as random number generators. To denote the losses doublets were used (two same figures on the both dies) (Halprin, R. and Naor, M., 2009), at the same time the doublets 1-1 и 2-2 meant "defective goods", other doublets meant "stand-by". The process imitation was integrated to the following operations:

1. Placing the initial shapes on the electroformed moulds;

2. Filling the forms with plastisol;

3. Closing the shapes hermetically;

4. Turning over the electroformed moulds for equidistribution of plastisol in the shape;

5. Putting the disks in the rotary oven;

6. Taking out the shapes from the forms;

7. Cutting off the edges of plastisol of the shapes.

Seven gamers imitated the production process in accordance with the game model offered to them. The trainer (the role "customer") set a task to make 10 items of goods. As a result, after the first iteration 6 items were produced with $\mathrm{OEE}=63 \%$.

For the second iteration, it was settled to refuse from the defective goods, thus for the "run" just the doublets 3-3, 4-4, 5-5 and 6-6 were left. As a results 8 items of goods were produced, OEE was $80 \%$.

So, it is evident that at eliminating machinery standbyes during 10 runs the required number of goods will be produced at $100 \%$ efficiency of the machinery.

To assess the degree of the personnel resistance before game modelling the information was required from the HR-Department. We got to know that in October this year the operators of the shop (12 people) were questioned, one fourth of the employees showed negative attitude to implementing lean manufacturing at their stage of production. A bit more than a half of all the employees showed their concern about the innovation, estimating their attitude to it as "rather negative than positive". The rest operators were neutral having answered that they did not have any definite meaning of the innovation. It is notable that none of the employees showed any wish to try the innovation. Thus, the level of resistance was quite high.

At the end of training the employees were asked again, what their meaning of implementing lean manufacturing tools was. As a result, two thirds gave a positive answer. Only one employee had kept a negative attitude. All the rest answered "rather positive than negative". It is evident that this rather exaggerated demonstration of impact of losses on the ultimate output contributed to decreasing resistance of the personnel of the enterprise.

\section{Conclusion}

To prove the hypothesis, we worked out a game model imitating assembly line production with successive operations. The theoretical model was probated at an enterprise producing children toys from rubber and plastic. There was a high degree of resistance of the personnel at the enterprise at the initial stage of implementing the system of lean manufacturing.

As a result of the game the participants realized the impact of production losses on the result and they got the skill of calculating the OEE which indicates the degree of performance. At the same time the gamers understood certain basics of lean manufacturing tools. This created a good basis for implementing lean manufacturing system at the enterprise.

The model worked out by the authors adds to a whole set of practical recommendations of developing production systems. The model is universal and is easily adaptable to a production process of any kind. The game is enough illustrated, so it can be used for explaining the processional approach in a non-production sphere. The model is easily applicable, which is its main advantage.

One of the means of checking the efficiency of the model in question is providing a feedback. To better understand how the personnel resistance depends on the level of their training one can use a detailed questionnaire before and after the game. The authors of the paper provided a feedback only after the training and it was done with the help of the forms offered by the HR-Department of the enterprise. The questionnaire before the training was done be the representatives of the enterprise. Incomplete understanding of the issues causing general resistance took place because of the fact that the questionnaires were processed by the HRDepartment. The final information was offered only in a summarized form. Still the managers of the enterprise put an aim of lessening the resistance of the personnel and it is to be admitted that the aim was achieved.

We think that the research has a broad sphere of practical applicability due to the fact that production development based on the principles of lean manufacturing has become very popular recently. A compilation of case-studies of different spheres is of great interest from the point of view of statistical data analysis

\section{References}

1. D. Bondarenko, The Algorithm of Success, 9-13 (2010)

2. J. Bruce, P. Scott, and M. Roberts, Investigating Employee Resistance to Lean Transformation (UK Academy for Information Systems, 2011)

3. N. Davydova, Lean Production (Institute of Economics and Management, Izhevsk, 2012)

4. E. Efromeeva, On the Classification of Methods and Models of IT Analysis. Universities for Tourism and Service Association Bulletin, 1 (2008)

5. A. Grinin, Management in a Kaizen style: How to reduce costs and increase profit (Alpina Publishing, 2012)

6. R. Halprin, and M. Naor, Games for Extracting Randomness (Weizmann Institute of Science, 2009) 
7. M. Kaizen Imai, The Key To Japan's Competitive Success (Irwin/McGraw-Hill, 1986)

8. M. Imai, Gemba Kaizen: A Commonsense Low-cost Approach to Management (McGraw-Hill, 1997)

9. K.E. Chong, A case study. 2015 IEEE International Conference on Industrial Engineering and Engineering Management (IEEM), 1427-1421 (2015)

10. A. Kovacheva, Challenges in Lean implementation (Aarhus School of Business, 2010)

11. W. Lareau, Office Kaizen: Transforming Office Operations Into a Strategic Competitive Advantage (ASQ Quality Press, 2002)

12. J. Liker, and D. Meier, The Toyota Way (McGrawHill Education, 2006)

13. R. Maurer, One Small Step Can Change Your Life: The Kaizen Way (Workman Publishing, 2004)
14. Kaizen for the Shop Floor: A Zero-Waste Environment with Process Automation (Productivity Press Development Team, 2002)

15. P. Rabunets, About the Production System of SIBUR (2011)

16. J. Van Ede, Shoveling waste out of the factory works better than using a bulldozer. Retrieved from Business-improvement.eu: Inspire Businesses to Flow. $\quad$ http://www.businessimprovement.eu/lean/Oce_Lean_Transformation.php.

17. J. Womack, and D. Jones, From Lean Production to the Lean Enterprise. Harvard Business Review (1994)

18. J.-M. Yien, The Turkish Online Journal of Educational Technology, 10(2), 1-10 (2011) 